\title{
Modified T Loop for High Labially Placed Maxillary Canine -A Case Report
}

\author{
Harshil Naresh Joshi', Jay Sureshkumar Soni², Mauli Shah' ${ }^{3}$, \\ Shireen Mann ${ }^{4}$, Rameshwar H Taluja ${ }^{5}$ and Swetha Taluja ${ }^{6}$ \\ ${ }^{1}$ K.M.Shah Dental College and hospital,SumandeepVidyapeeth,Piparia, Waghodia,Vadodara,Gujarat,India. \\ ${ }^{2,3}$ Ahmedabad Dental College \&t Hospital, Ahmedabad, Gujarat, India \\ ${ }^{4} B D S$, Nation Dental College and Hospital, Punjab, India \\ ${ }^{5} B D S, M D S$ (ProsthodontistandImplantologist) \\ ${ }^{6} B D S, P G C O I$ (DentalSurgon) \\ Corresponding author email: drharshiljoshi11@gmail.com
}

\section{ABSTRACT}

A 14-year-old female presented with ectopically erupted upper canines and she has a Class I molar relation on both sides. First premolar extraction was planned to correct the ectopic position of canines. Segmental (TMA) titanium molybdenum alloy T-loop was used to retract the canines into an ideal position in the upper arch. Post-treatment results showed a correction of ectopically erupted canines, bilateral Class I molar relation maintained, and inclination of incisors improved. At the end of treatment, the patient showed a pleasing smile with an improved smile arc.

\section{KEY WORDS: SEGMENTAL ARCHWIRE, T-LOOP, LOOP MECHANICS.}

\section{INTRODUCTION}

Anterior teeth retraction represents a fundamental phase of fixed orthodontic appliance treatment. Three-dimensional control of anterior teeth movement and correct positioning of teeth are essential for the maintenance of function, esthetics, and stability of orthodontic treatment (Braun et al., 1997; Felemban et al., 2013). The space closure stage of orthodontic tooth movement is achieved through two types of mechanics. The first type is sliding mechanics and involves either moving brackets along an archwire, which is sliding the archwire through brackets and tubes. This leads to friction, which results in adverse rotational movements and decreased tooth movement, and increases in anchor requirements or both. Therefore, the name friction is often associated with it (Pacheco et al., 2012; Rossouw and Friction, 1976).

Biosc Biotech Res Comm P-ISSN: 0974-6455 E-ISSN: 2321-4007

\section{crossef}

Identifiers and Pagination

Year: 2021 Vol: 14 No (6) Special Issue

Pages:33-35

This is an open access article under Creative

Commons License Attribn 4.0 Intl (CC-BY).

DOI: $h t t p: / / d x . d o i . o r g / 10.21786 / b b r c / 14.6 .7$
In the second type, frictionless mechanics, i.e. loops can be fabricated in a segmental or full archwire and closing loops are usually used in loop mechanics for the extraction of space closure. The major advantage of segmental loop mechanics is the lack of friction between the bracket and archwire during space closure. The disadvantages associated with this technique are the undesired tooth rotations in the transverse, sagittal planes and are time-consuming in fabricating the loops (Burstone and Koenig, 1976).

Case Report: A 14-year-old female patient in the permanent dentition presented with the chief complaint of irregularly placed upper and lower front teeth. The patient had a mesocephalic head, mesoprosopic facial form with a mild convex profile, and competent lips. The patient had Angle's class I molar relation. Cephalometric analysis indicated an orthognathic maxilla and mandible with mild proclination in upper and lower anterior teeth on skeletal class I jaw bases with average growth pattern. The patient had highly labially placed 13 and 23. The overjet was $1 \mathrm{~mm}$, and the overbite was $2 \mathrm{~mm}$. The mandibular midline had shifted $2 \mathrm{~mm}$ to the left side from the facial midline.(Fig. 1a to 1e, $2 \mathrm{a}$ to2c) Carey's and arch perimeter analysis showed $12 \mathrm{~mm}$ of tooth material

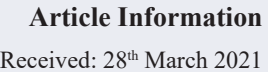

Received: $28^{\text {th }}$ March 2021

ccepted after revision: $29^{\text {th }}$ May 2021 
excess in the maxillary arch and $8 \mathrm{~mm}$ of tooth material excess in the lower arch.

Treatment plan: Following a comprehensive clinical and database analysis, a treatment plan involving extraction of the upper and lower first premolars with maximum anchorage protocol to achieve a symmetrical buccal occlusion, midline correspondence, appropriate overjet, and adequate retraction of the proclined upper and lower anterior was devised. Maximum anchorage was planned to retract canines and prevent mesial movement of the molars. To correct the High labially placed canine, a modified T-loop was planned along with a transpalatal arch in the maxilla. The proximity of the canine root to the lateral incisor's root was the need for the modification, the additional horizontal arm was added in the $\mathrm{T}$ loop so that more transitive movement can be achieved.

Treatment progress: Segmental arch mechanics involving T-loop in the upper arch. MBT appliance with $0.022 \times$ 0.028 " slot was used. To reduce the treatment time, a continuous archwire was placed in the maxillary arch bypassing the maxillary canine. The Modified T loop was attached to the maxillary right canine. $0.017 \times 0.025$ " titanium molybdenum alloy (TMA) T-loop was employed at the bracket of ectopic canine and accessory molar tube.(Fig. 3) T-loop was activated by $3 \mathrm{~mm}$ at subsequent appointments. The activation was done by pulling the distal arm and cinching it distal to the first molar (Mulligan, 1980; Mishra HA and Mishra RA, 2018).
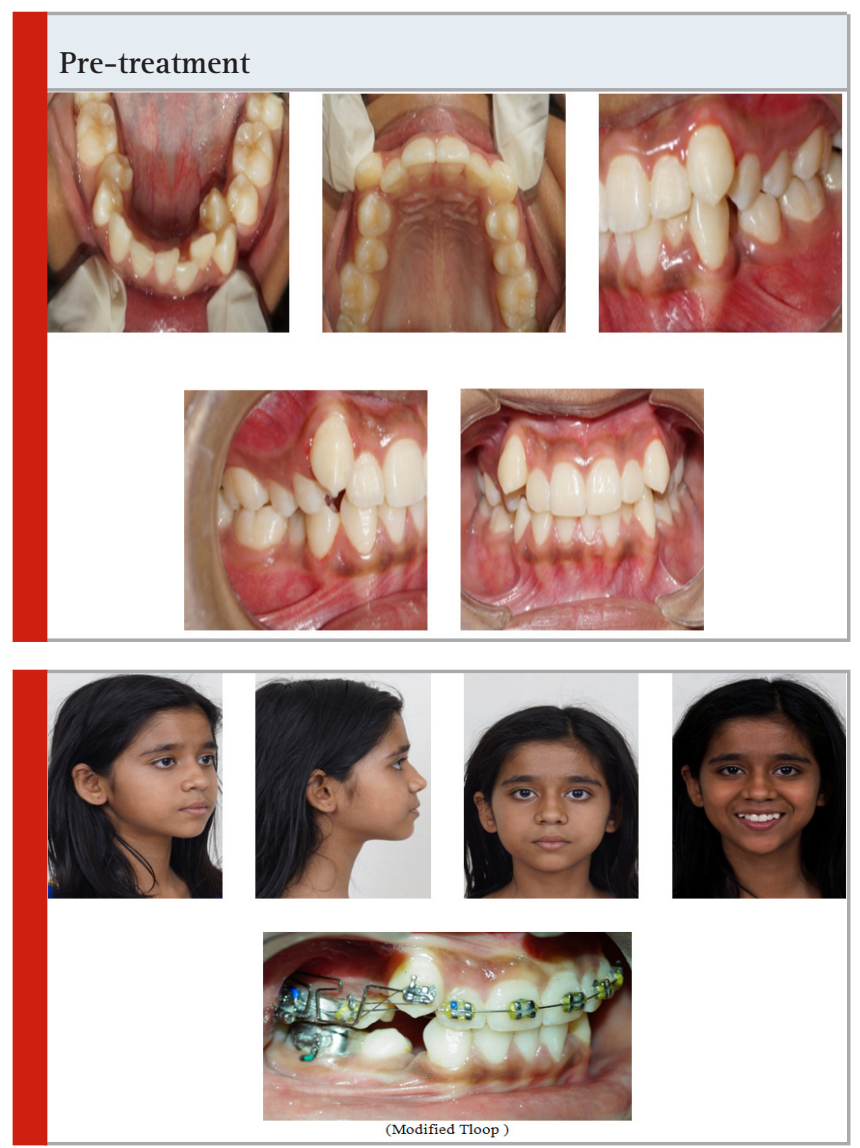

After individual canine retraction, alignment, and leveling, both dentitions was accomplished with the following sequence of arch wires:

a. $0.016 \times 0.022$ " heat-activated nickel titanium archwires

b. $0.017 \times 0.025$ " stainless steel archwires

c. $0.019 \times 0.025$ " stainless steel archwires along with Active tie-backs to close remaining extraction space closure in the maxillary and mandibular arch.
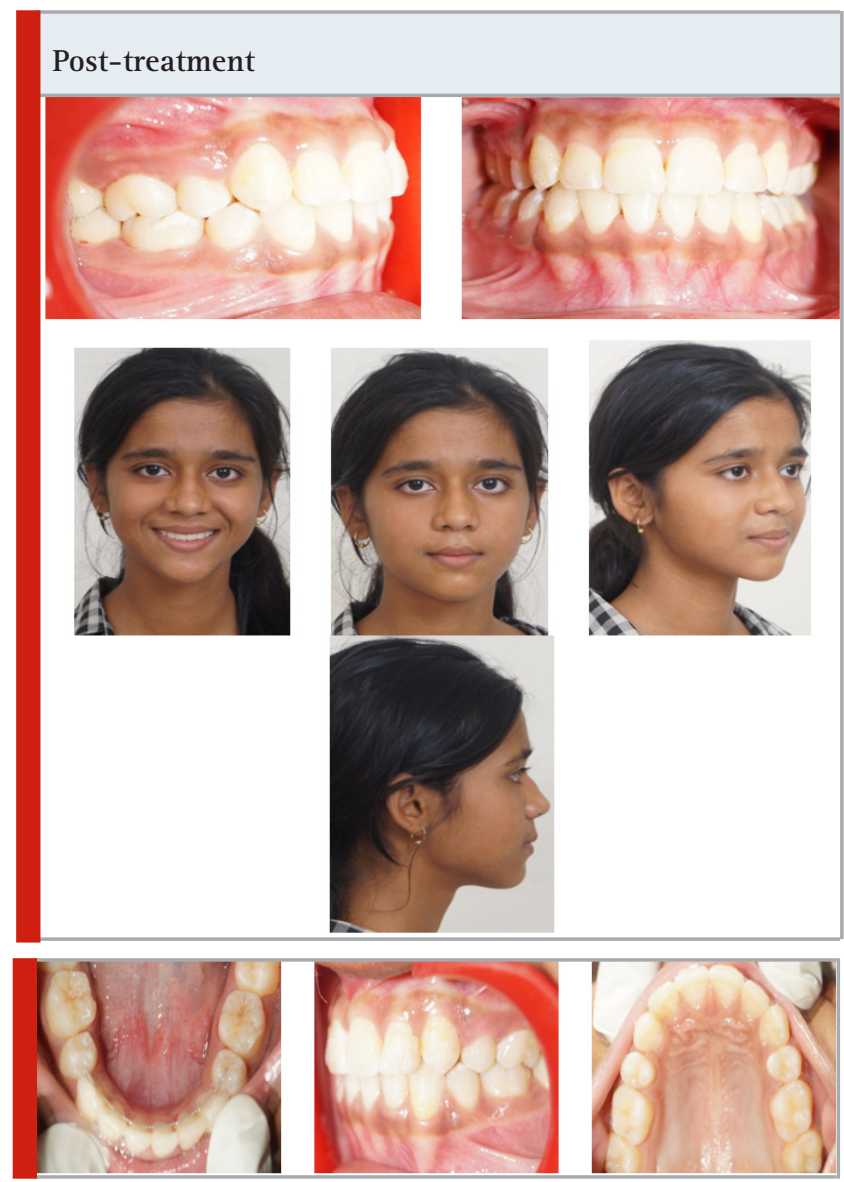

Treatment Results: The post-treatment results for the patients showed excellent improvement in a smile. (Fig 4a to 4e \&t 5a to 5d) Maxillary and mandibular anterior teeth proclination with the crowding was corrected with good maintenance of the buccal occlusion, and Class I molar relation bilaterally maintained throughout the treatment with correction of the overjet and overbite. Post-treatment intraoral photographs and lateral cephalogram showed that the maxillary and mandibular incisors were inclined appropriately. The panoramic radiographs showed adequate root parallelism in both upper and lower arches. For the retention, Hawley's appliance was given for the maxillary arch \&t a fixed lingual retainer was bonded for the mandibular arch.

\section{DISCUSSION}

The T-loop has been recognized as an effective means to achieve desired tooth movement by differential 
moments between the anterior and posterior segments. The modified T loop can be used where the position of the maxillary canine is high labially placed along with root proximity of the adjacent tooth. The use of TMA wire and increase in the wire length help in reducing the loaddeflection rate. Incorporating adequate alpha and beta bends into the loop can give rise to the ideal moment-toforce ratio required for tooth movement. As there is no sliding of the wire in between the brackets, the friction is not involved and hence helps with the anchorage control during the initial canine retraction (Vaidya et al., 2018). However, precise control of tooth movement is possible in a predictable manner with the T-loop. The T-loop with asymmetric shape could be used to achieve a moment differential. Maintenance of the moment differential as the extraction spaces close improves anchorage control and force system predictability (Sanjay et al., 2015; Matsui et al., 2002).

\section{CONCLUSION}

Precisely made T-loop produces the ideal momentforce ratio for controlled tooth movement in all three dimensions. Modified T loop will be more useful in cases with high labially placed canine for better Crown- Root control and very useful in cases with extreme crowding and cases requiring maximum anchorage.

\section{REFERENCES}

Braun, S., Sjursen Jr, R.C. and Legan, H.L., 1997. On the management of extraction sites. American journal of orthodontics and dentofacial orthopedics, 112(6), pp.645-655.

Burstone, C.J. and Koenig, H.A., 1976. Optimizing anterior and canine retraction. American journal of orthodontics, 70(1), pp.1-19.

Burstone, C.J., 1982. The segmented arch approach to space closure. American journal of orthodontics, 82(5), pp.361-378.
Felemban, N.H., Al-Sulaimani, F.F., Murshid, Z.A. and Hassan, A.H., 2013. En masse retraction versus two-step retraction of anterior teeth in extraction treatment of bimaxillary protrusion. Journal of orthodontic science, 2(1), p.28.

Latchoumi, T.P., Ezhilarasi, T.P. and Balamurugan, K., 2019. Bio-inspired weighed quantum particle swarm optimization and smooth support vector machine ensembles for identification of abnormalities in medical data. SN Applied Sciences, 1(10), pp.1-10.

Matsui, S., Otsuka, Y., Kobayashi, S., Ogawa, S. and Kanegae, H., 2002. Time-saving closing loops for anterior retraction. Journal of clinical orthodontics: JC0, 36(1), pp.38-41.

Mishra, H.A. and Maurya, R.K., 2016. An approach with hybrid segmental mechanics. Journal of clinical and diagnostic research: JCDR, 10(6), p.ZD18.

Mrudul, V., Pai, P., Jyothikiran, H., Raghunath, N. and Ranjan, A., 2018. Orthodontic treatment of a crowding case using segmental arch technique: A case report. International Journal of Medical and Dental Case Reports, 5(1), pp.1-3.

Mrudul, V., Pai, P., Jyothikiran, H., Raghunath, N. and Ranjan, A., 2018. Orthodontic treatment of a crowding case using segmental arch technique: A case report. International Journal of Medical and Dental Case Reports, 5(1), pp.1-3.

Pacheco, M.R., Jansen, W.C. and Oliveira, D.D., 2012. The role of friction in orthodontics. Dental Press Journal of Orthodontics, 17(2), pp.170-177.

Sanjay, N., Rajesh, R.N.G., Scindia, R. and Ajith, S.D., 2015. Space closure with loop mechanics for treatment of bimaxillary protrusion: a case report. Journal of international oral health: JIOH, 7(5), p.65.

Vaidya, M., Jyothikiran, H., Raghunath, N. and Pai, P., 2018. Extraction versus non-extraction: A retrospective study. International Journal of Orthodontic Rehabilitation, 9(1), p.23. 